\title{
Complicated gastric duplication cyst presenting as cystic intraperitoneal collection: a case report
}

\author{
Muhammad Bilal Mirza ${ }^{1 *}$ D, Asim Shahzad ${ }^{1}$, Nasir Mahmood ${ }^{1}$, Ahmed Imran², Mahvish Hussain ${ }^{3}$, Zafar Fayyaz $^{4}$ and \\ Nabila Talat ${ }^{1}$
}

\begin{abstract}
Background: Alimentary tract duplications are rare anomalies and any delay in the diagnosis may develop various complications. Infection, hemorrhage, or perforation of the duplication cyst may lead to an acute presentation. Occasionally, it may lead to a diagnostic and management dilemma. Herein, we report an unusual complication of gastric duplication cyst.

Case presentation: A 2.5-year-old girl presented with recurrent abdominal distension, fever, and abdominal pain. The imaging workup revealed a huge intraperitoneal collection. Intraoperatively, a huge pseudocyst was encountered communicating with the gastric duplication cyst. The gastric duplication cyst was sharing a common wall with the greater curvature of the stomach but was not communicating with the gastric lumen. Pseudocyst along with gastric duplication cyst was completely excised. The resultant seromuscular defect of the stomach was also closed. The postoperative period was uneventful.

Conclusion: Perforation of the gastric duplication cyst should be kept in differentials of intraperitoneal collection not amenable to multiple aspirations. Huge intraperitoneal collection secondary to perforation of gastric duplication is exceedingly rare and scarcely reported in the literature.
\end{abstract}

Keywords: Gastric duplication cyst, Intraperitoneal collection, Pseudocyst, Liver abscess, Case report

\section{Background}

Alimentary tract duplications are rare anomalies and commonly diagnosed in the first few years of life [1]. Delayed diagnosis or misdiagnoses often leads to the occurrence of complications [2]. Gastric duplications cyst accounts for $4-7 \%$ of alimentary tract duplications. It may develop complications such as infection of the cyst, peritonitis secondary to its perforation, and hemorrhage $[3,4]$. Herein, we present a unique presentation of complicated gastric duplications cyst that proved a diagnostic as well as management dilemma.

\footnotetext{
*Correspondence: blmirza@gmail.com

'Department of Pediatric Surgery, The Children's Hospital and the Institute of Child Health, Lahore, Pakistan

Full list of author information is available at the end of the article
}

\section{Case presentation}

A 2.5-year-old girl presented in the outpatient department with progressive abdominal distension for the last 6 months, and abdominal pain (appreciated as inconsolable cry), and fever for the last 5 days. Past medical history showed that the girl initially presented at the age of 1 year with fever and abdominal pain in the Gastroenterology Department. Ultrasound followed by CT scan (Fig. 1) of the abdomen was performed which gave a suspicion of liver abscess. The abscess was aspirated under ultrasound guidance, and a pigtail catheter was inserted. The patient was discharged in good condition. However, a month later, the patient again presented with an epigastric swelling in addition to abdominal pain and fever. Examination revealed a fluctuant inflammatory epigastric swelling with upper 


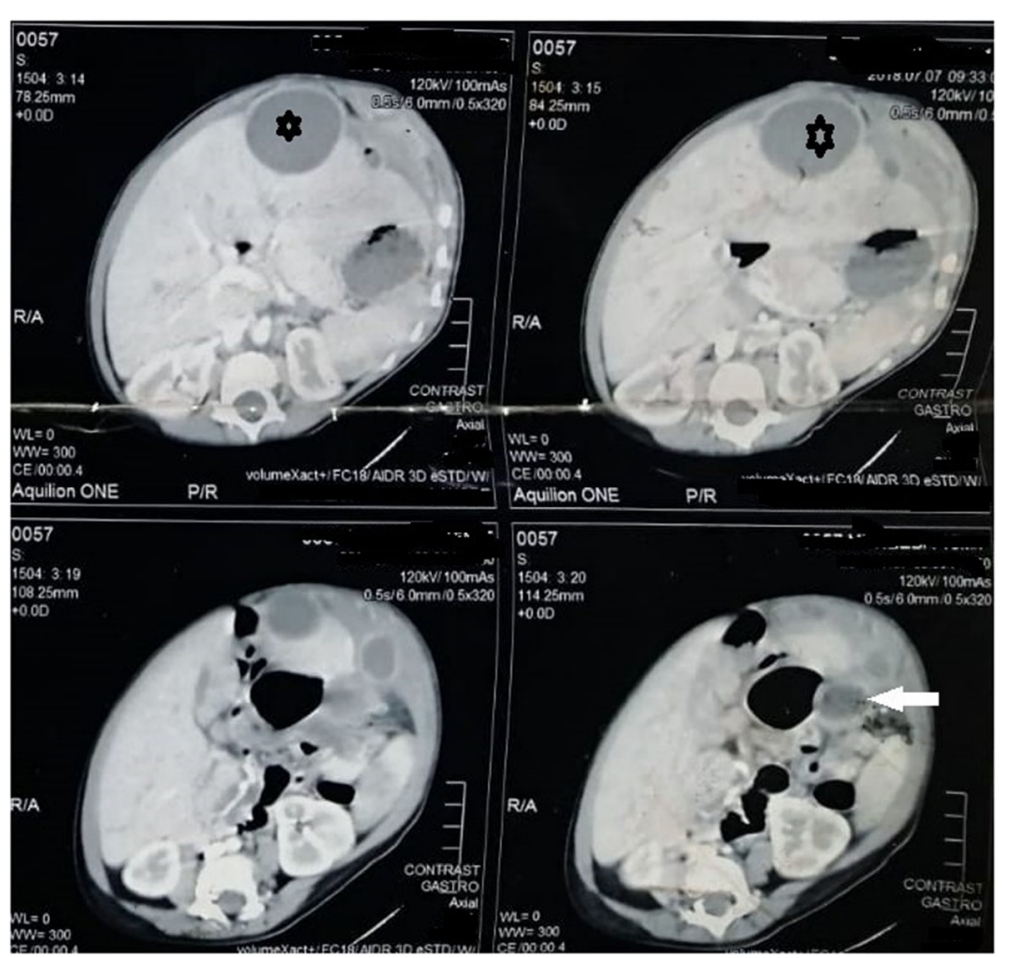

Fig. 1 Showing a well-circumscribed collection in the left lobe of the liver $\left(^{*}\right)$. Note a hypodense area in relation to stomach representing gastric duplication cyst (white arrow)

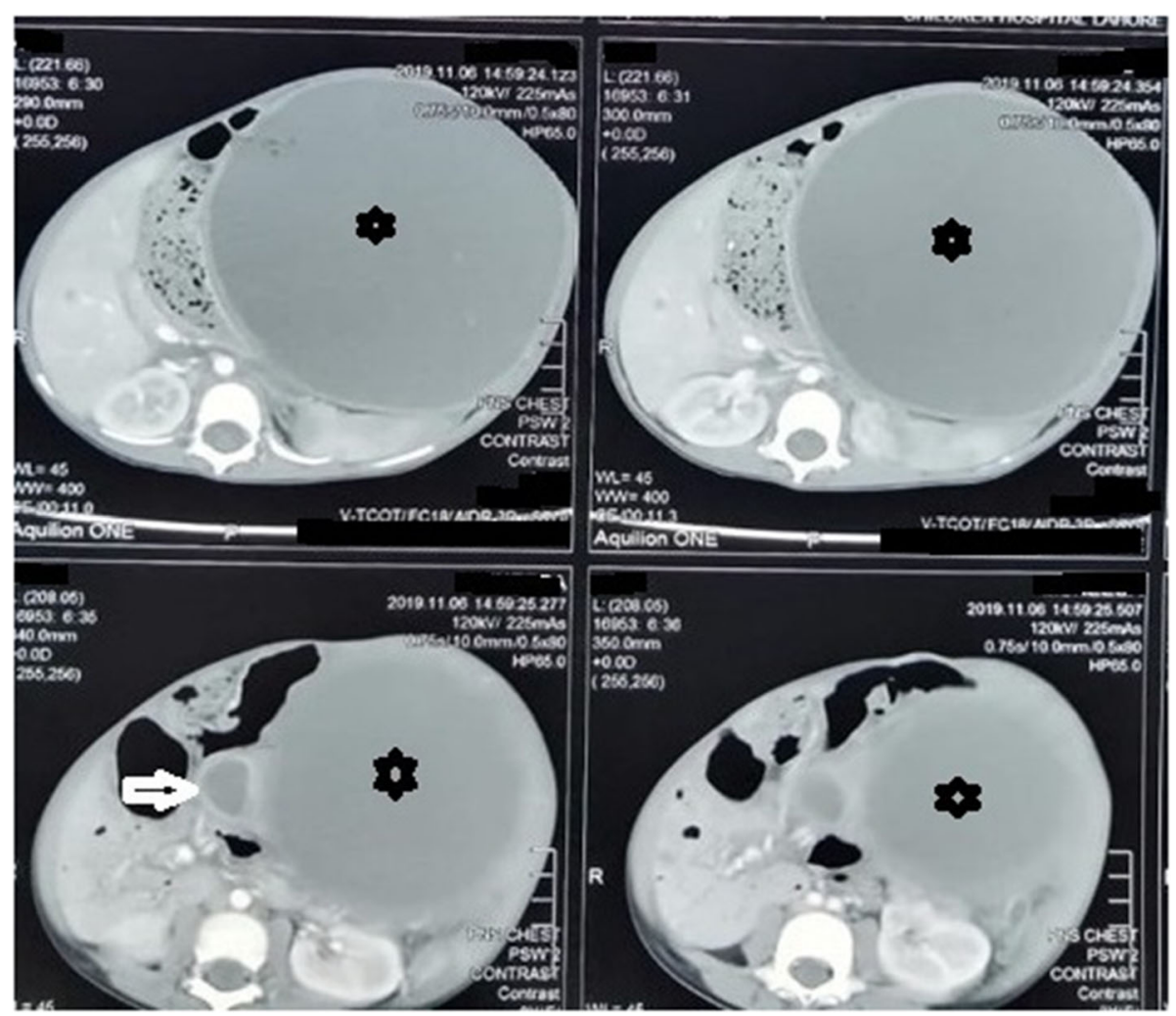

Fig. 2 Showing a huge cystic collection in the abdomen (*). Note a hypodense area in relation to stomach representing gastric duplication cyst (white arrow) 


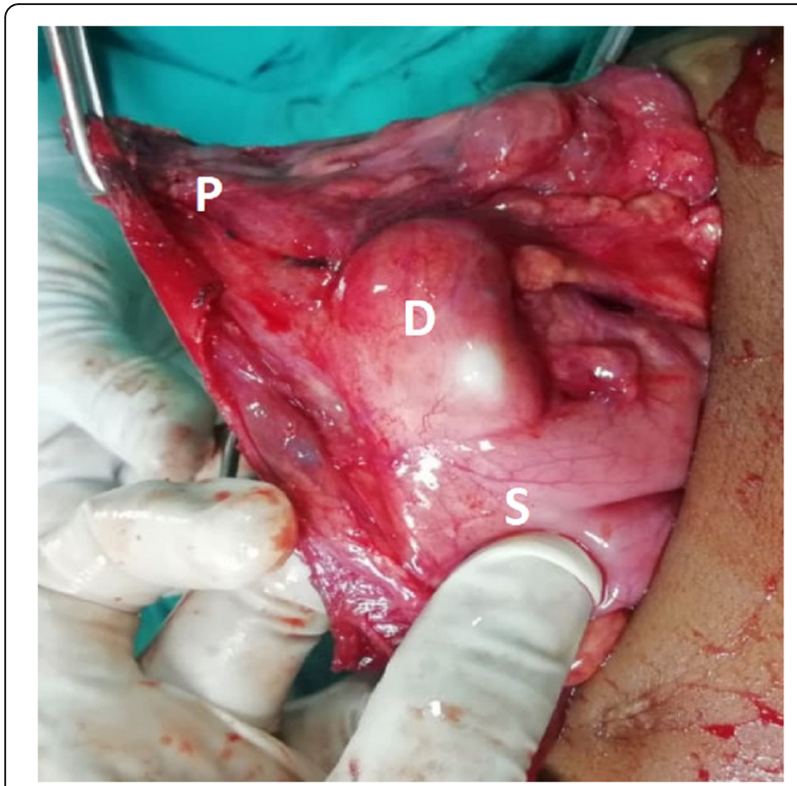

Fig. 3 Intraoperative photograph showing gastric duplication (D) intimately attached to the greater curvature of the stomach (S). The opened pseudocyst $(P)$ is also visible

abdominal distension. CT scan performed again and showed a residual abscess in the left lobe of the liver, tracking into the epigastrium. The patient was shifted to the Pediatric Surgery Department where open drainage of the abscess was done. About $150 \mathrm{ml}$ frank pus was drained. Postoperatively, the fever did not settle; follow-up ultrasound revealed residual abscess which was aspirated (ultrasound-guided). The histopathology showed a pyogenic abscess, but no organism could be detected on cultures. The patient was then discharged in good condition.

During current admission, she was febrile with the following vitals: temp $101{ }^{\circ} \mathrm{F}$, pulse $116 / \mathrm{min}, \mathrm{R} / \mathrm{R} 24 / \mathrm{min}$, and BP 90/60. The abdomen was distended with mild tenderness in the upper abdomen; a cystic mass $(14 \times 10$ $\mathrm{cm}$ ) was palpable in the epigastrium and left hypochondrium. The lower abdomen was soft with normal bowel sounds. The rest of the systemic examination was unremarkable. The patient was admitted to the ward and an ultrasound was planned, but during admission, the patient became suddenly pale with accentuation of abdominal distension. The $\mathrm{CBC}$ which was initially $8 \mathrm{~g} / \mathrm{dl}$ dropped to 3 $\mathrm{g} / \mathrm{dl}$ when repeated. The patient also developed tachycardia and tachypnea. The patient was managed with IV fluids and packed red blood cells were transfused. After stabilization, an urgent CT scan was performed which showed a cystic intraperitoneal collection (Fig. 2).

The patient underwent exploratory laparotomy electively using a supraumbilical transverse abdominal incision. There was a huge cyst in the epigastrium and left hypochondrium, filled with hemorrhagic fluid. The cyst was aspirated to assist its dissection from surrounding viscera. The cyst had communication with another smaller cyst that was intimately attached to the greater curvature of the stomach (Fig. 3). Both cysts were excised leaving behind a small seromuscular defect of the greater curvature of the stomach which was repaired with a single layer of interrupted sutures. Postoperative recovery was uneventful, and the patient was discharged in good clinical condition on the 7th postoperative day. Figure 4 describes the timeline of the events. The histopathology of the bigger cyst divulged as a pseudocyst, whereas that of the smaller cyst as gastric duplication cyst. The patient is doing fine on a follow-up of 12 months.

\section{Discussion}

Alimentary tract duplications are characterized by intimate contact with any part of the gastrointestinal tract (GIT), smooth muscles in the wall, and lined by the mucosa of GIT. These are named after the part to which they are intimately attached [1]. Gastric duplication cysts are usually attached to the greater curvature of the stomach and often do not communicate with the gastric lumen [5]. In the present case, the gastric duplication cyst was not communicating with the gastric lumen and fulfilled all the criteria of a classical GIT duplication cyst.

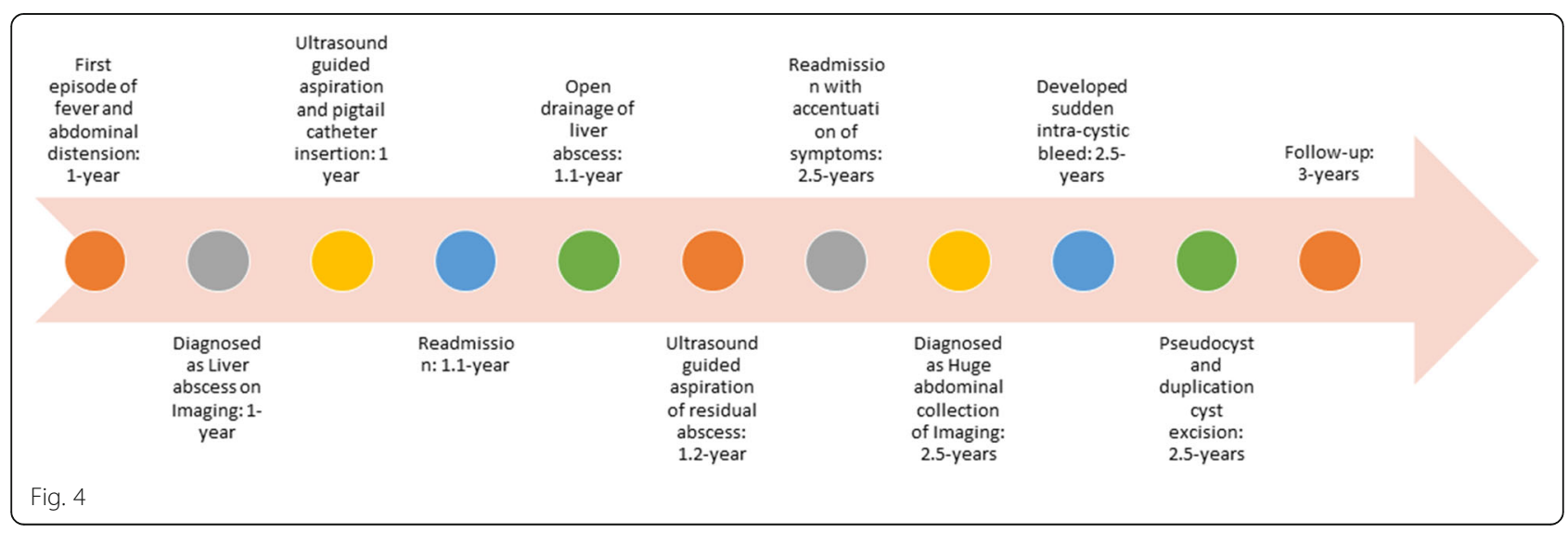




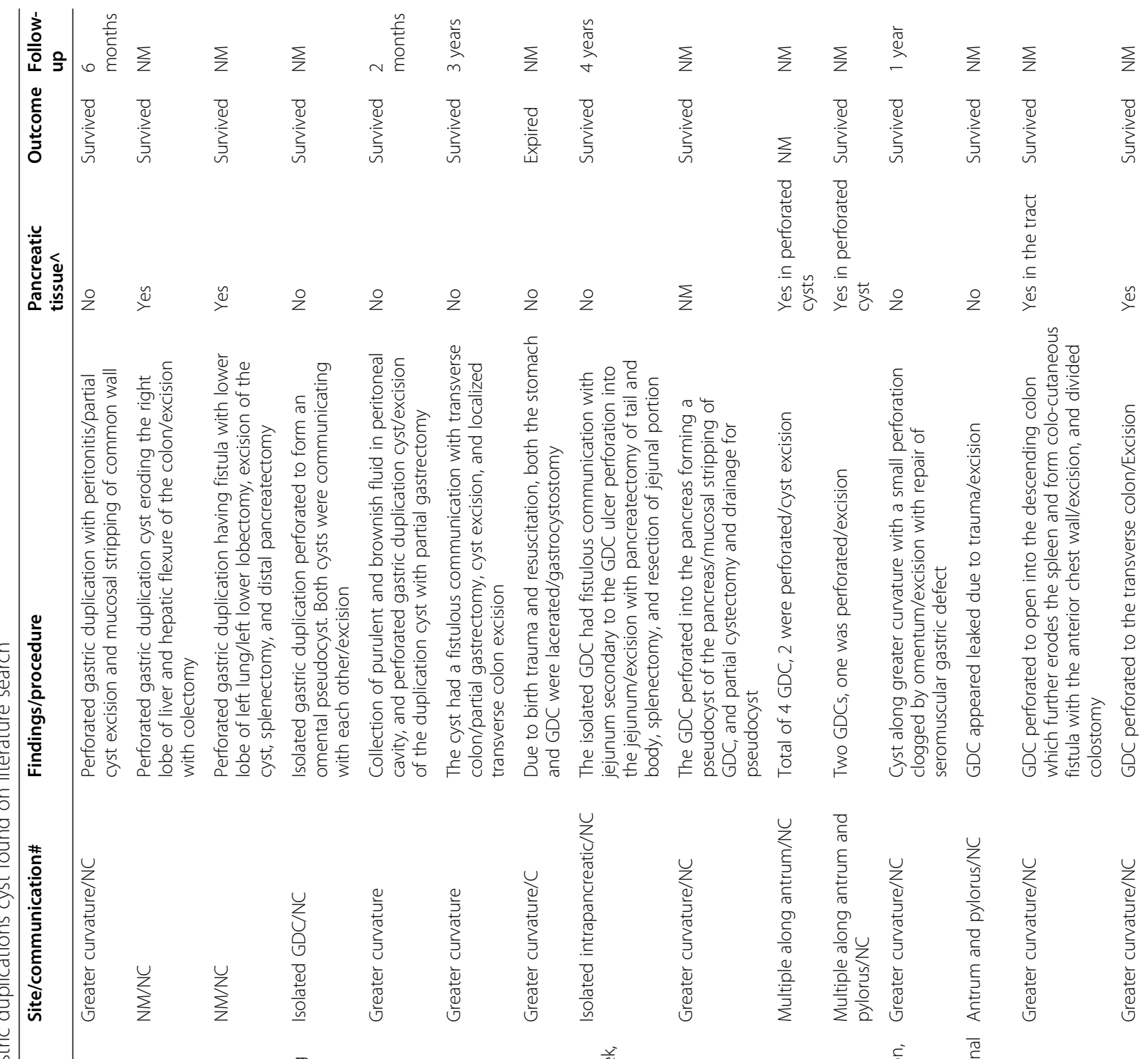

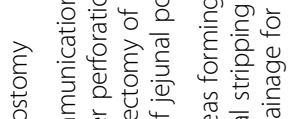

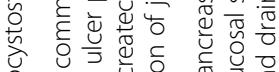

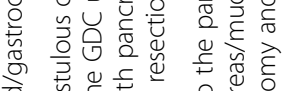

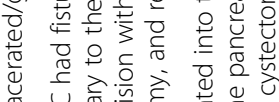

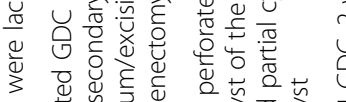

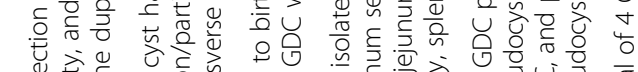

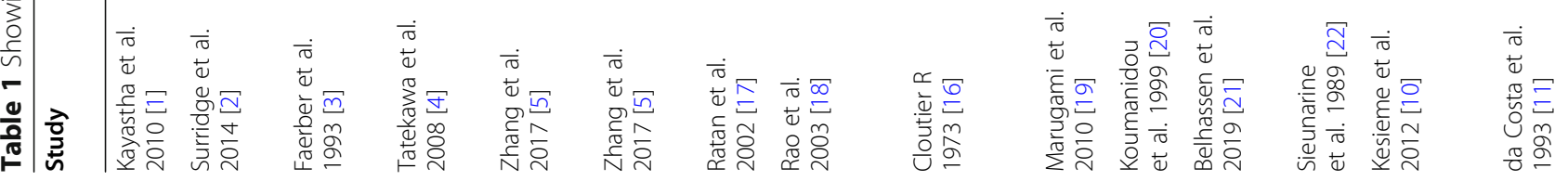

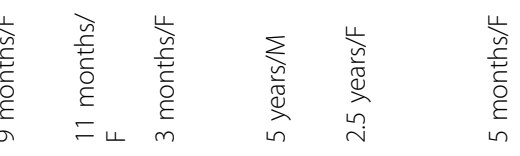




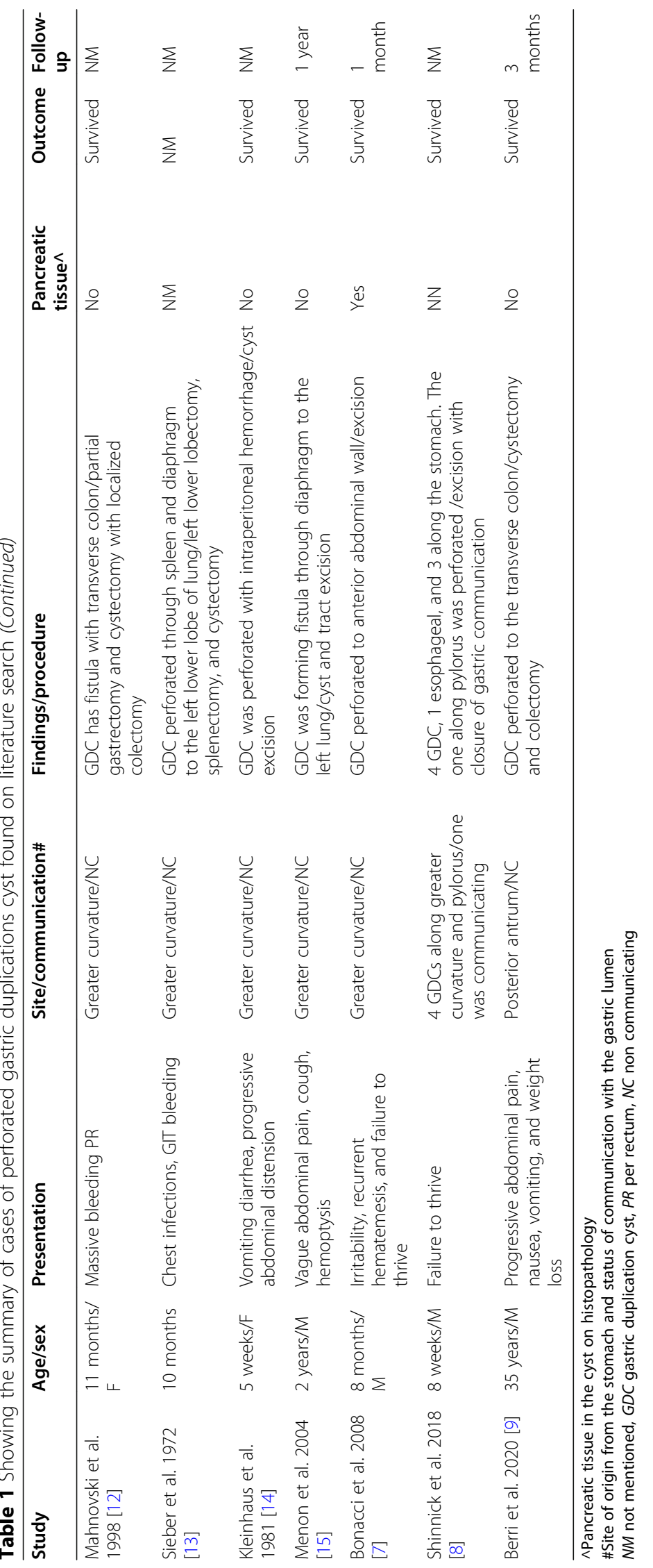


Gastric duplication cyst often presents variably ranging from merely incidental finding to as severe as acute peritonitis or hemorrhagic shock. Those arising from the antropyloric region may impinge the gastric outlet and thus present with vomiting. Few communicating gastric duplication cysts may present with hematemesis [6]. Infection or perforation of the cyst may result in an acute abdomen, thus necessitating urgent surgical intervention [1]. Occasionally, the patient may develop anemia secondary to spontaneous bleeding within the cyst. In the present case, multiple complications were encountered accounting for delayed as well as inappropriate management. Most plausibly, a perforation of gastric duplication cyst brought about peritonitis which was initially simulated liver abscess; later, it might have developed a huge pseudocyst that masqueraded the associated gastric duplication cyst.

The diagnosis can be based on imaging studies. X-rays may show the mass effect of large duplication cyst but unable to confirm the diagnosis. Ultrasound abdomen may aid in diagnosis by showing gut signature sign of the cyst, but this is an operator-dependent modality. A contrast-enhanced CT scan is an investigation of choice for the diagnosis of GIT duplications. It will show relations of the cyst with the surrounding viscera. Any complications if present will also be delineated well by this modality [6-8].

The present case was a diagnostic as well as a management challenge. On initial presentation, it was reported as hepatic abscess and dealt with erroneously. Subsequently, the patient developed sudden accentuation of cyst size due to intracystic bleeding as depicted by the appearance of sudden pallor in the present case. CT scan again could not identify the gastric duplication though on the retrospective review of the CT films, a hypodense cystic structure could be seen in relation to the stomach (Fig. 1 and 2).

An extensive literature review was performed regarding the perforated gastric duplication cyst. About 22 cases of perforated gastric duplication could be retrieved (Table 1). The gastric duplication cyst after perforation may either cause peritonitis [1] or it may develop fistulous communication with the structures in the vicinity. The fistulous communications are reported with the colon, pancreas, spleen, anterior abdominal wall, and lower lobe of the left lung through the diaphragm [9-15]. Interestingly, 2 cases of pseudocysts formation are also reported as a complication of perforated gastric duplication cyst $[4,16]$.

The ultimate management is complete surgical excision as malignant transformations in gastric duplications have been reported. The excision may involve a partial gastrectomy if a small gastric area is involved [12]. In case of extensive gastric attachment, excision of the free part and mucosal stripping of the common wall is preferred [1]. In the present case, the gastric duplication was completely excised leaving behind a serosal defect which was repaired.

\section{Conclusion}

Complications in gastric duplication cyst may lead to misdiagnosis and maltreatment. Careful reporting of imaging investigations is required to identify these lesions as they can masquerade the actual pathology leading to diagnostic and management issues.

\section{Abbreviations \\ CT scan: Computerized tomography scan; CBC: Complete blood count; R/ R: Respiratory rate; BP: Blood pressure; GIT: Gastrointestinal tract}

\section{Acknowledgments}

Nil.

Authors' contributions

MBM along with AS, and NT, drafted the manuscript and performed the literature review. NM was the operating surgeon and contributed in the manuscript drafting. Al wrote the radiological section in addition to major contribution in manuscript drafting. MH wrote the histopathological section in addition to major contribution in manuscript writing. ZF wrote the gastroenterology section in addition to major contribution in manuscript drafting. The authors read and approved the final manuscript.

\section{Funding}

Nil.

Availability of data and materials

Record is available in the department.

\section{Ethics approval and consent to participate}

NA

\section{Consent for publication}

Informed written consent from parents has been taken and can be sent when required.

\section{Competing interests}

None.

\section{Author details}

'Department of Pediatric Surgery, The Children's Hospital and the Institute of Child Health, Lahore, Pakistan. ${ }^{2}$ Department of Pediatric Radiology, The Children's Hospital and the Institute of Child Health, Lahore, Pakistan.

${ }^{3}$ Department of Histopathology, The Children's Hospital and the Institute of Child Health, Lahore, Pakistan. ${ }^{4}$ Department of Pediatric Gastroenterology, Hepatology, and Nutrition, The Children's Hospital and the Institute of Child Health, Lahore, Pakistan.

Received: 19 April 2020 Accepted: 10 November 2020

Published online: 10 December 2020

References

1. Kayastha K, Sheikh A. Gastric duplication cyst presenting as acute abdomen: a case report. APSP J Case Rep. 2010;1:6.

2. Surridge CA, Goodier MD. Gastric duplication cyst: a cause of rectal bleeding in a young child. Afr J Paediatr Surg [serial online] 2014 [cited 2020 Oct 2];11:267-8. Available from: http://www.afrjpaedsurg.org/text. asp?2014/11/3/267/137340..

3. Faerber EN, Balsara R, Vinocur CD, de Chadarevian JP. Gastric duplication with hemoptysis: CT findings. AJR Am J Roentgenol. 1993;161:1245-6.

4. Tatekawa Y, Hoshino N, Urita Y, Kudou S, Komuro H, Hori T, et al. Omental pseudocyst formation associated with perforated gastric duplication: a case report. J Pediatr Surg. 2008;43:e27-9. 
5. Zhang L, Chen Q, Gao Z, Xiong Q, Shu Q. Diagnosis and treatment of gastric duplication in children: a case report. Exp Therap Med. 2017;14: 3062-6.

6. Youssef A, Ibrahim A, AlShehabi Z, Omran A, Sharara Al. Gastric duplication cyst presenting as massive gastrointestinal bleeding. Pediatr Gastroenterol Hepatol Nutrition. 2019;22:189-92.

7. Bonacci JL, Schlatter MG. Gastric duplication cyst: a unique presentation. J Pediatr Surg. 2008;43:1203-5.

8. Shinnick JK, Jain S, Alazraki AL, Durham MM. Ruptured thoracic and abdominal gastrointestinal duplication cysts presenting with failure to thrive. Pediatr Emerg Care. 2018;34:e128-30.

9. Berri T, Mazouzi S. Gastric duplication cyst fistulized with the colon in an adult: a case report. Surg Pract. 2020;24:37-9.

10. Kesieme EB, Dongo AE, Osime CO, Olomu SC, Awe OO, Eze Gl, et al. Gastric duplication: a rare cause of massive lower gastrointestinal haemorrhage, chest wall mass, and enterocutaneous fistula. Case Rep Gastrointest Med. 2012;2012:250890

11. da Costa JM, Mariz CM, de Sousa JA, Gonzaga RA, de Sousa RM, dos Santos NT. Gastric duplication presenting rectal bleeding. A clinical case supporting McLedtchie's theory. Arq Gastroenterol. 1993;30:62-4.

12. Mahnovski V, Mahour GH, Rowland JM. Gastric duplication-colonic fistula with colonic ulceration and bleeding. J Pediatr Surg. 1998;33:1815-6.

13. Sieber WK. Perforated gastric duplication with pulmonary communication: a case report. J Pediatr Surg. 1972;7:257.

14. Kleinhaus S, Boley SJ, Winslow P. Occult bleeding from a perforated gastric duplication in an infant. Arch Surg. 1981;116:122.

15. Menon P, Rao KL, Saxena AK. Duplication cyst of the stomach presenting as hemoptysis. Euro J Pediatr Surg. 2004;14:429-31.

16. Cloutier R. Pseudocyst of the pancreas secondary to gastric duplication. J Pediatr Surg. 1973;8:67.

17. Ratan SK, Ratan J, Lohan A, Roychaudhary R. Unusual presentation of gastric duplication cyst in a neonate with pneumoperitoneum and vertebral anomalies. Am J Perinatol. 2002:19:361-6.

18. Rao KL, Sunil I, Pimpalwar A, Vaiphei K, Chowdhary S. Intrapancreatic gastric duplication cyst presenting as lower gastrointestinal bleeding. J Pediatr Surg. 2003;38:243-4.

19. Marugami N, Hirai T, Yamashita N, Yoshida M, Ohishi H, Hiquchi B, et al. A case of perforated multiple gastric duplication cysts with five-layered appearance on ultrasonography. J Med Ultrasonics. 2010;38:47-51. https:/ doi.org/10.1007/s10396-010-0282-7.

20. Koumanidou C, Montemarano H, Vakaki M, Pitsoulakis G, Savvidou D, Kakavakis K. Perforation of multiple gastric duplication cysts: diagnosis by sonography. Euro Radiol. 1999;9:1675-7.

21. Belhassen S, Ammar S, Zouaoui A, Abdellatif N. Asymptomatic perforated gastric duplication clogged by omentum, anorectal malformation and agenesis of the corpus callosum: a rare combination. Afr J Paediatr Surg. 2019;16:46-8.

22. Sieunarine K, Manmohansingh E. Gastric duplication cyst presenting as an acute abdomen in a child. J Pediatr Surg. 1989;24:1152.

\section{Publisher's Note}

Springer Nature remains neutral with regard to jurisdictional claims in published maps and institutional affiliations.

\section{Submit your manuscript to a SpringerOpen ${ }^{\circ}$ journal and benefit from:}

- Convenient online submission

- Rigorous peer review

- Open access: articles freely available online

- High visibility within the field

- Retaining the copyright to your article

Submit your next manuscript at $\boldsymbol{\nabla}$ springeropen.com 